\title{
Erratum to: Low-temperature creep in pure metals and alloys
}

M. E. Kassner ${ }^{1, *}$ (D), K. K. Smith ${ }^{1}$ (1), and C. S. Campbell ${ }^{1}$ (1)

${ }^{1}$ Department of Aerospace and Mechanical Engineering, OHE430, University of Southern California, Los Angeles, CA 90089-1453, USA

Published online:

22 August 2017

(C) Springer Science+Business

Media, LLC 2017

Erratum to: J Mater Sci (2015) 50:6539-6551

DOI 10.1007/s10853-015-9219-2

This erratum corrects Fig. 3a-c, with 3a-d below. The original figures do not include an important 1-year RT (longest in the literature) creep test at a stress $(15 \mathrm{MPa})$ less than the yield stress at a conventional strain rate $10^{-4} \mathrm{~s}^{-1}$.

The online version of the original article can be found under doi:10.1007/s10853-015-9219-2.

Address correspondence to E-mail: kassner@usc.edu 


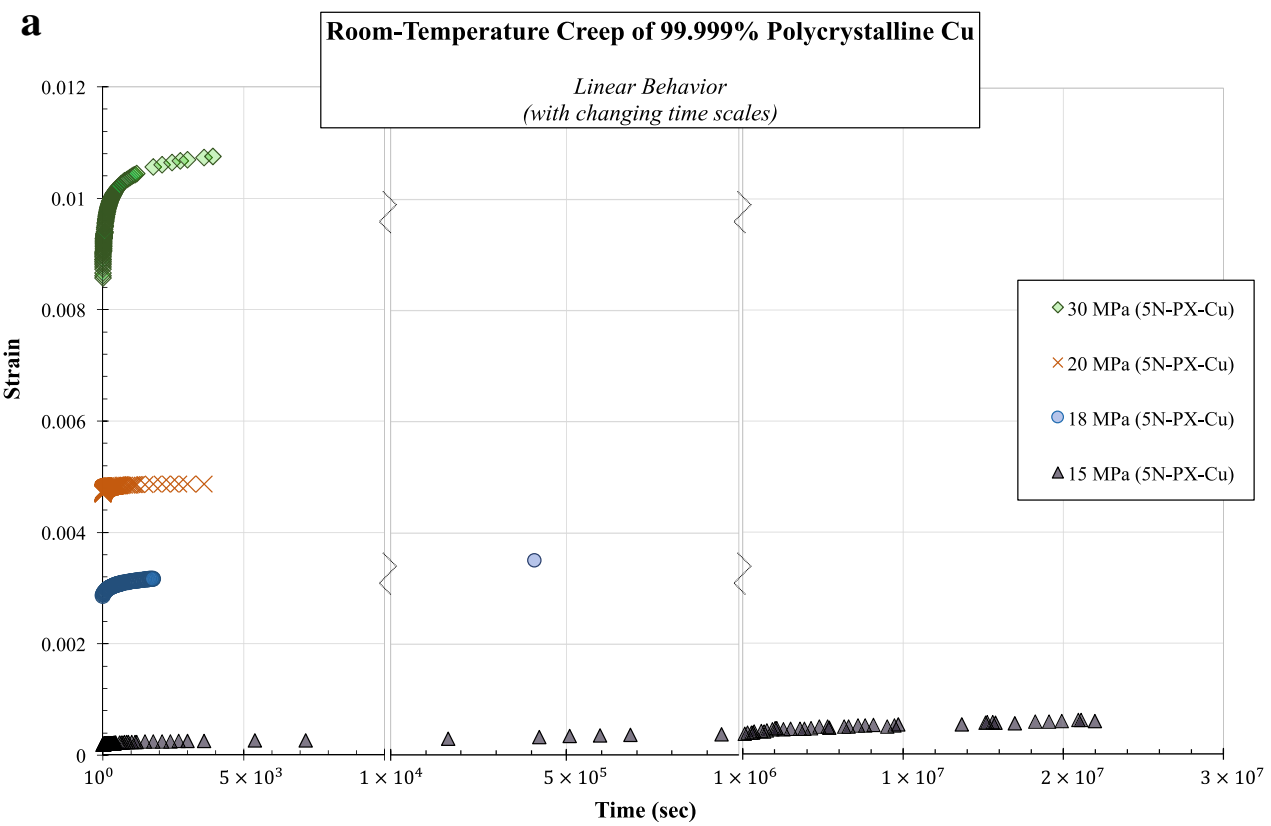

Figure 3a was never included in the original manuscript. The original strain-time (linear) is now included along with $3 \mathrm{a}$ also now including the 1-year copper test.

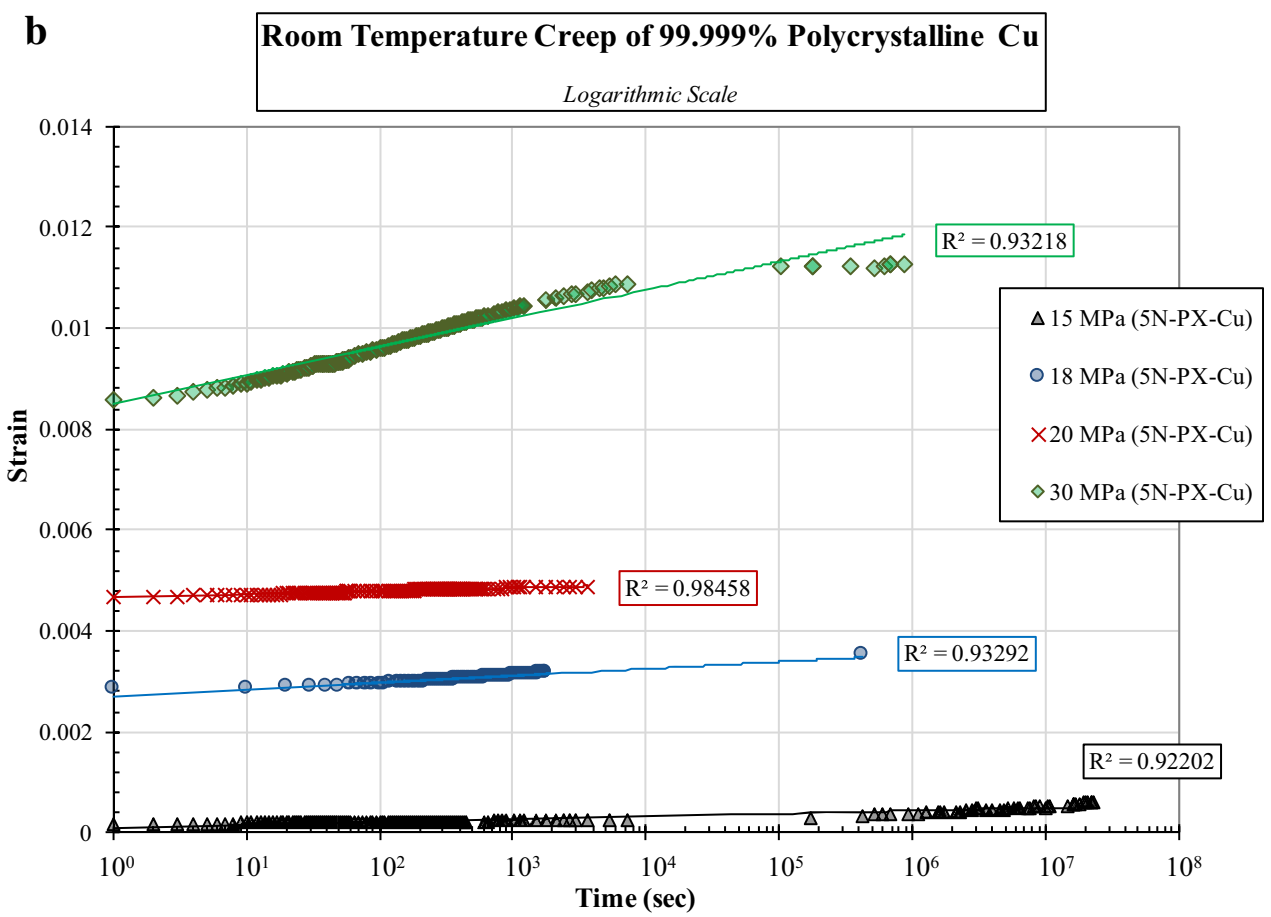

Figure $3 \mathrm{~b}$ now includes the 1-year copper test and replaces Fig. a in the original manuscript. 


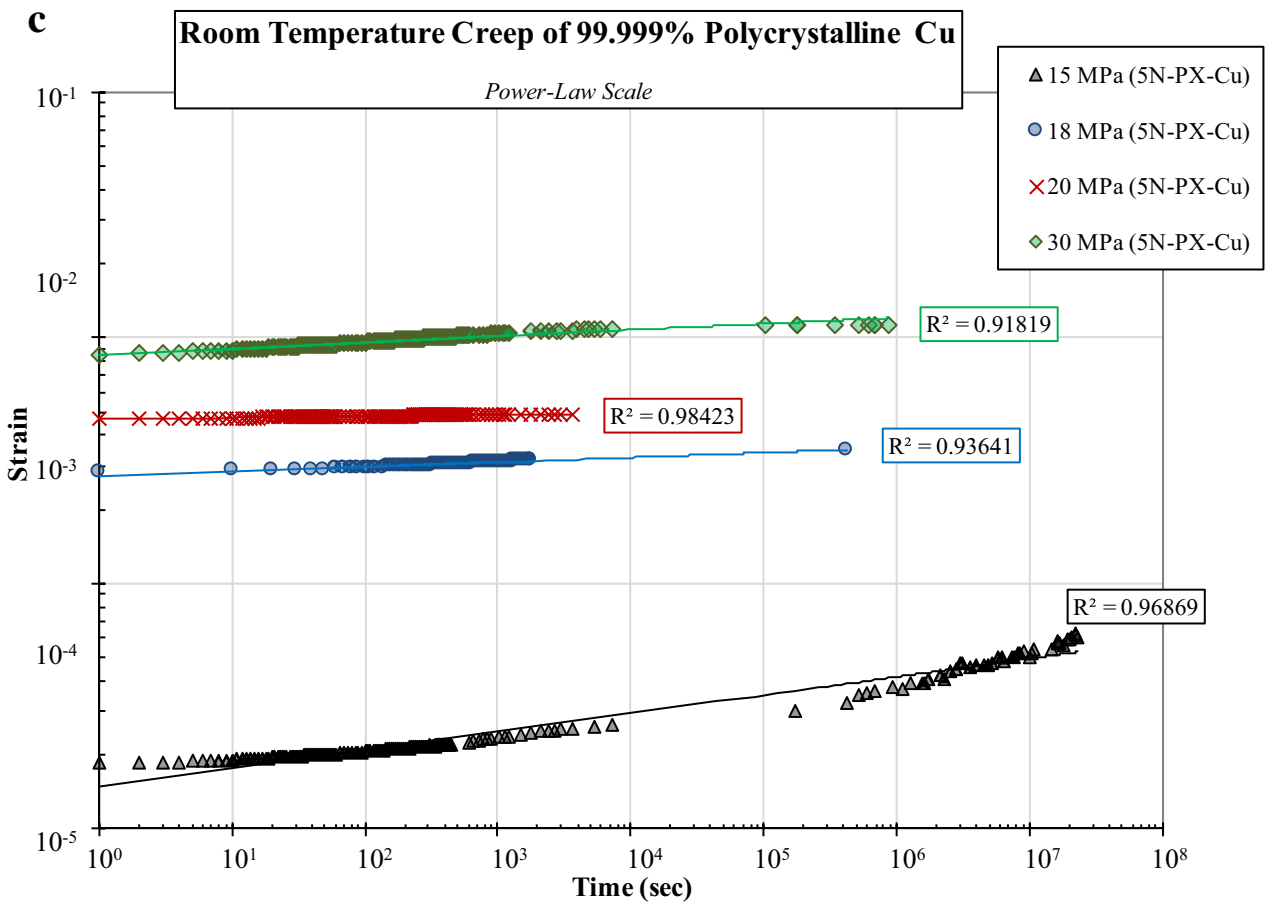

Figure 3c now includes the 1-year copper test and replaces Fig. $\mathrm{b}$ in the original manuscript.

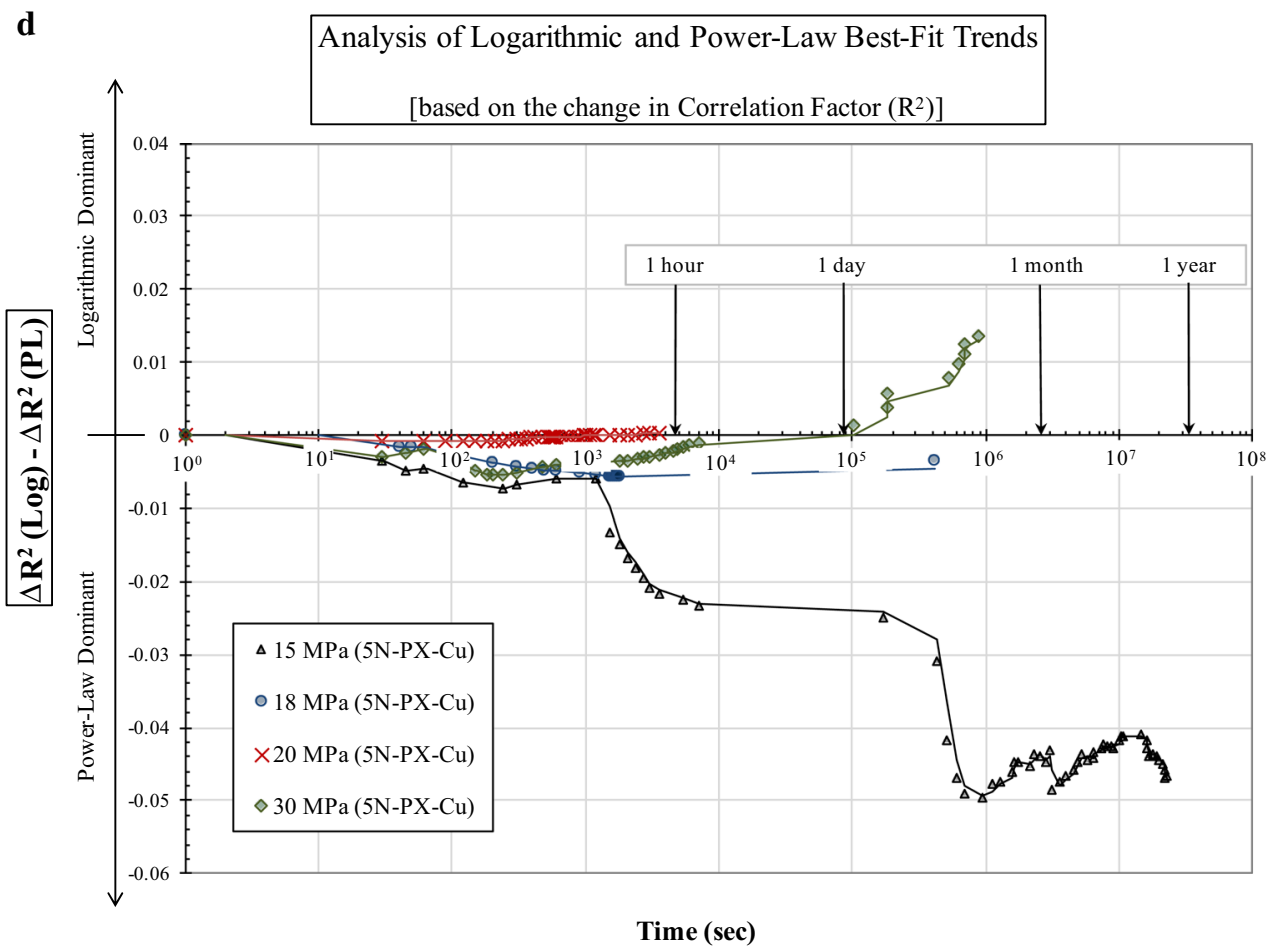

Figure $3 d$ with replaced $3 c$ in the manuscript reports the difference in the quality for logarithmic and power law fits with the addition of a 1-year copper creep test below the conventional yield stress. The quality of fits with strain and stress varies; new low stress at longer times shows PL behavior, and 
higher stress at longer times shows log behavior. Lower stress to longer time evinces logarithmic behavior. For shorter times $(<1 \mathrm{~h})$ PL and log may equally describe the data.

Also, not included in the original paper are two RT creep silver tests Figs. $\mathrm{Xa}$ and $\mathrm{Xb}$, one above and one below the conventional yield stress $(25 \mathrm{MPa})$ determined at a conventional strain rate of $10^{-4} \mathrm{~s}^{-1}$. RT creep tests on silver are rare. The Ag behavior is inconsistent with the Seeger model discussed in the original manuscript.
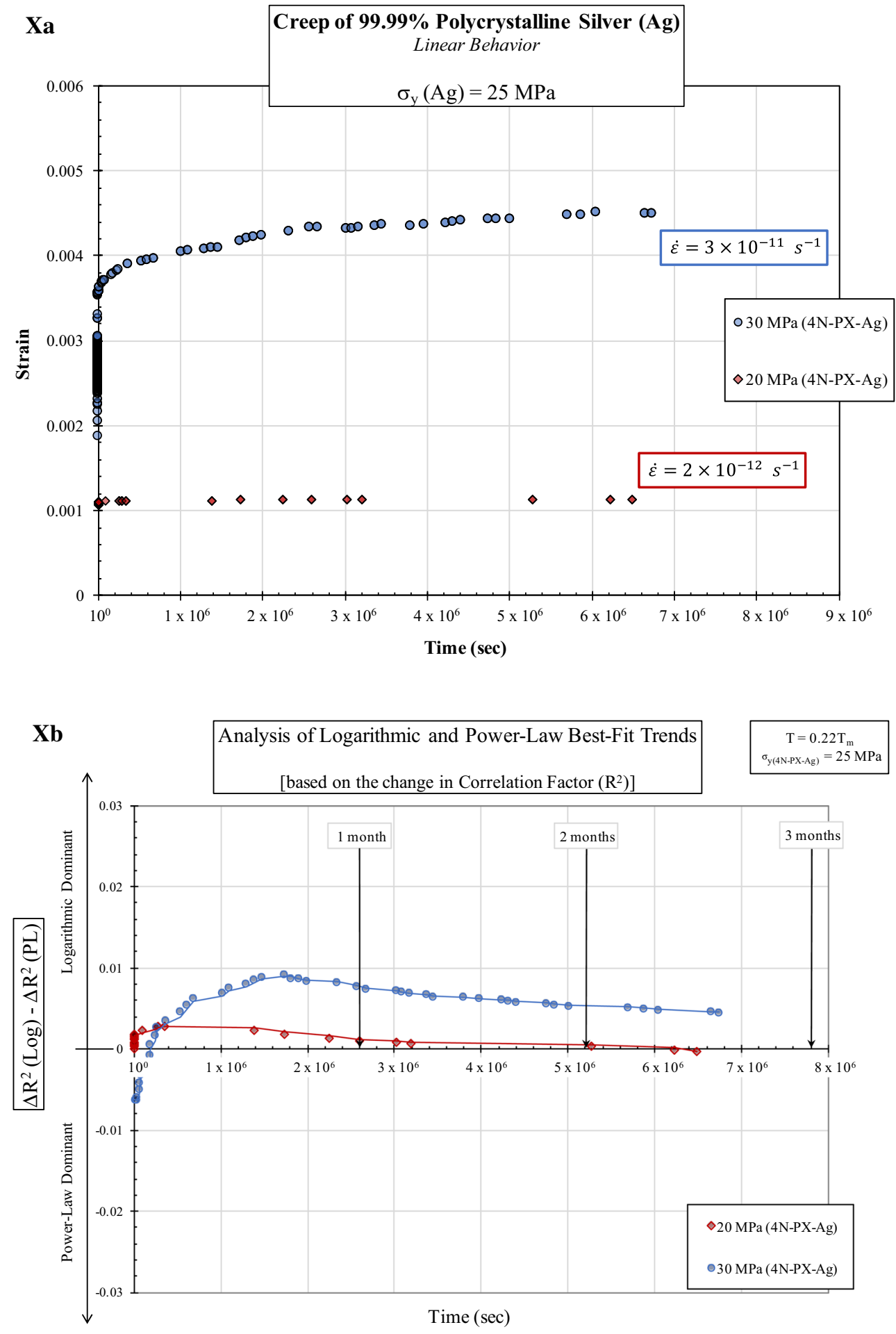